\title{
Violence Risk Assessment in Forensic Nurses' Clinical Practice: A Qualitative Interview Study
}

\author{
Helen Olsson $\mathrm{PhD}^{1}$ \& Lisbeth Porskrog Kristiansen $\mathrm{PhD}, \mathrm{RN}^{2,3}$ \\ ${ }^{1}$ School of Education, Health and Social Studies, Dalarna University, Sweden \\ ${ }^{2}$ Department of Nursing Sciences, Mid Sweden University, Sweden \\ ${ }^{3}$ Department of Health and Caring Science, Faculty of Health and Occupational Studies, University of Gävle, \\ Sweden \\ Correspondence: Helen Olsson, School of Education, Health and Social Studies, Dalarna University, SE-791 88, \\ Falun, Sweden. Tel: 46-(0)23-77-8611; 46-(0)73-27-01-711. E-mail: hol@du.se
}

Received: September 5, 2017 Accepted: October 12, 2017 Online Published: October 17, 2017

doi:10.5539/gjhs.v9n12p56 URL: https://doi.org/10.5539/gjhs.v9n12p56

\begin{abstract}
Background: The legislation of Swedish forensic psychiatric care states that the risk of further violence must be assessed before a patient is granted release from a forensic psychiatric hospital. The aim of the study was to describe the experiences of forensic nurses with in-patient risk assessment processes, and their implication for daily clinical forensic praxis.

Method: Semi-structured interviews with staff who were involved in the patients risk assessment process. The interview texts were analyzed using qualitative latent content analysis.

Discussion: The forensic nursing staff has to deal with many contradictory realities. The description was about being able to balance between supporting their work with an EBP approach of risk assessment while trying to establish interpersonal relationships and to allow for positive meetings with the patient. The study indicated that staff used a multiple sources of knowledge in order to make credible and accurate risk assessments.

Conclusions: If the risk assessment process are to be used in a legally secure manner, the staff must receive regular support from team leadership that can provide both guidance and training. Based on a holistic approach, the link between the instinct of staff and their work with structured risk assessment must be founded on routines and solid platforms.
\end{abstract}

Keywords: forensic clinical practice, nurses' experiences, violence risk assessment

\section{Introduction}

The main purpose of all forensic psychiatric care is to prevent relapse into crime. In Sweden, the legislation states that the forensic units also must provide good quality care, in which the patient must be involved (SFS 2017:30), and that the risk of future violence must be assessed before a patient is granted release from a forensic psychiatric hospital (SFS 2017:38). Therefore, Swedish forensic psychiatry on a regular basis assesses the prognosis of risk of interpersonal violence. Good quality care should be knowledge-based and legally secure (SFS 2017:30), and should be grounded on assumptions that are consistent with evidence-based practice (EBP). Sackett, Richardson, Rosenberg and Haynes (1997) define EBP as being a combination of research, clinical experience, and patients' preferences. Making use of scientifically tested methods, in this case the use of a risk-assessment instrument, is one way of ensuring that forensic care has an evidence-based approach.

A well-validated instrument that is widely used internationally is The Historical, Clinical and Risk Management Scheme (HCR-20), which assesses the general propensity for violent behaviour in criminal and psychiatric populations (Webster, Douglas, Eaves, \& Hart, 1997). HCR-20 latest version is called HCR-V3, which has been translated into more than 20 languages and probably the world's most popular violence risk assessment instrument (Hart, Webster, Douglas, \& Belfrage, 2013).

A risk assessment (RA) indirectly indicates how successful the forensic treatment has been in reducing the risk of violence, and whether or not it affected clinical care of high-risk patients and contributed to reduced restrictions for low-risk patients (Olsson, Strand, Kristiansen, Sjöling, \& Asplund, 2013). In violence-risk research, there is broad 
agreement that an absolute risk is impossible to establish (Sing, Fazel, Gueorguieva, \& Buchanan, 2014) and, further, that a RA constantly needs updating (Nilsson, Munthe, Gustavson, Forsman, \& Anckarsäter, 2009).

\subsection{Different Steps in the Process of Forensic Risk Assessment}

A RA can be seen as a process taking place on several different levels. Firstly, the patient must be involved and informed about its purpose and content. Secondly, the forensic professionals perform the risk assessment approximately every six months. Thirdly, based on the outcome of the risk assessment, the court makes a decision as to whether or not the current patient should be discharged from compulsory treatment and released into community (Buchanan, 2013). Further, at the clinical level, nursing staff must incorporate the outcome of the risk assessment into their daily clinical work with the patient, which sometimes leads to revisions in the patient's treatment plan.

\subsection{Challenges Related to Forensic Risk Assessment}

There are many challenges related to the risk-management process, which requires well-functioning, professional interaction where all the forensic professionals involved in the patient care participate. For example, one challenge for clinicians in long-stay forensic units is to stay objective and neutral in the RA of patients (Samuels, O'Driscoll, \& Bazaley, 2005). Further, it is challenging to ensure that an assessment does not result in discrepancies between how the forensic nursing staff perceive risk, and how the team or individual risk assessor scores the patient risk (Samuels et al., 2005). Besides, it is not uncommon that the risk assessor is also the caregiver of the patients, which could result in conscientious risk analysis (Nilsson et al., 2009). Finally, one of the most significant challenges of how well clinicians succeeded in implementing knowledge into practice, is whether or not they are guided by a visionary leadership and work in a care unit where participation and reflexive learning are encouraged (Harvey \& Kitson, 2016).

There is still a great gap between best practice and actual clinical care (Belfrage, 1998; Grol \& Wensing, 2004; Storey, Watt, \& Hart, 2015), in this case the routine use of a RA instrument in daily forensic practice. There has been a great deal of research on violence RA and management in recent years, which has proven to be beneficial for forensic patient care regarding a better transparency of care (e.g. Otto \& Douglas, 2010; Sing, Grann, \& Fazel, 2011). However, research in the field of RA consists predominantly of violence prevalence, patient violence prevalence and characteristics. In spite of this, this is an area where two paradigms meet - the caring and the RA paradigm: there is barely any research that focuses on the experiences that forensic nurses have with RA in daily forensic practice or the way they deal with RA. The aim of this study was to describe the experiences of forensic nurses with in-patient RA processes, and their implications for daily clinical forensic praxis.

\section{Method}

The study used an inductive approach and a qualitative design with a latent content analysis inspired by Graneheim and Lundman (2004), and Patton (2015) to gain insight into and an understanding of the variation in the experiences of forensic nurses with the RA process, and its relation and impact on clinical care.

\subsection{Sample and Research Context}

The study sample consisted of 13 forensic nurses from a maximum-security forensic clinic with five care departments: the 13 forensic nurses were purposively selected as they met the inclusion criteria of being "especially knowledgeable forensic staff" in terms of risk assessment, reduced risk for violence and recovery processes in forensic care. In previous studies (Olsson et al., 2014; 2015), these nurses had been identified by 13 forensic inpatients as supportive and valuable in their recovery. All participants had assigned as key nursing staff for an individual patient. Interviews with the nurses were carried out from June to August 2012. Four participants were registered nurses and nine were assistant nurses. Six of the participants were female and seven were male, and their average age was forty (range 30-60 yrs). Their average time in the profession was seven years (range 2-35 yrs). When the participants had acknowledged their interest and selected a place for interview, an informed consent of participation was requested.

In the assessment of risk, the HCR-20 instrument was used, and a special risk-assessment team consisting of 5-6 staff members (e.g. psychiatrists, psychologists, social workers, and other members of staff) was responsible for the compilation of a RA of a patient. After the assessment, a consultation between the risk team and the patient's key nursing staff was arranged. Sometimes there was agreement as to the patient's risk level; sometimes a more in-depth discussion to reach agreement as to a RA was needed. Current forensic clinics have used RA instruments in daily practice since 1997 (see Belfrage, 1998). 


\subsection{Data Collection}

Purposeful sampling was used and individual audio-recorded, semi-structured qualitative face-to-face interviews with 13 nurses were conducted. An interview guide with open-ended questions was used and two main questions were asked: "What experiences do you have when it comes to the significance of patient RA for violence?" and "In your experience, how does the use of RA impact the clinical daily care of the forensic patient?" Ethical permission was given by the Regional Research Ethics Committee in Umeå, Sweden (07/164M).

\subsection{Data Analysis}

The interviews were transcribed verbatim (producing 20 double-spaced pages). The qualitative data were subsequently analyzed using qualitative content analysis (Guba, 1981; Graneheim \& Lundman 2004). The analysis started with several re-readings, focusing on what participants actually stated during the interviews. Meaning units were identified based on text that dealt with the same content. These meaning units were condensed while their essential meaning was retained. The next step involved coding - that is to say, the condensed units were coded. Finally, based on an interpretation and abstraction of the experiences, themes were created, while keeping the study as a whole in mind.

\section{Findings}

The findings showed that the nurses had different experiences in terms of how the valued the significance of conducting a patient-RA. This resulted in two main patterns. One pattern represented a high awareness of RA impact on daily patient care, while the other pattern showed that the RA was considered of minor significance. These patterns are reflected in the two following themes: "Experiencing a professionalization of the RA approach" and "Experiencing the RA as being a contra caring praxis". These are shown in Table 1 below.

Table 1. Showing the sub-themes with the related main-themes

\begin{tabular}{ll}
\hline Sub-Themes & Main-Themes \\
\hline Relying on an evidence-based approach & THEME 1. \\
Being alert and negotiating & Experiencing a professionalization of the RA approach \\
\hline Having a non-instrumental patient view & THEME 2. \\
Being reluctant in terms of the RA & Experiencing the RA as being a contra caring praxis \\
\hline
\end{tabular}

\subsection{Theme 1. Experiencing a Professionalization of the RA approach}

The findings showed that the RA was seen to be a factor that enhanced the quality of forensic care and that it was highly appreciated by the clinical nursing staff. There was also relative agreement that the RA was valuable in terms of current nursing praxis as it reduced arbitrariness. The involvement of the RA teams was appreciated by the forensic nurses as the interactions between these two principal staff groups, where one was nearer to the patient and the other further from the patient, on an aggregated level, balanced the total picture of the patient's health. Some of the interviewees also stated that it was difficult to be neutral and objective in the RAs and further that they lacked the ability to recognize and judge their own role in the care process.

\subsubsection{Relying on an Evidence-Based Approach}

This sub-theme reflected the experiences with the RA instrument HCR 20 as being an important element in the care provided since it helped maintain the quality of care. Previously - meaning before the introduction of the structured patient RA - it was experienced a more random and uncertain form of assessment. A member of staff with decades of experience within forensic nursing described the RA developments: "... now there is a kind of a structure and maybe, in the future, there might be another way to assess danger that is even better... anyway, there is a huge difference between now and when I started".

Nowadays, there can be a more objective and reliable judgement of status of the forensic inpatient as the assessment is conducted by others and not just the staff closest to the patient. One nurse stated the following: "...I think that the RA with HCR 20 is an important part of our work, although some people think it's bullshit.... but before now, we didn't do anything, only the patient rounds... and sometimes it went very bad, and sometimes the assessment succeeded.... Before it was more random... now (with the RA) it is more scientific and secure..." 


\subsubsection{Being Alert and Negotiating}

The use of the RA instrument provided a picture of the patient's progress and/or non-progress. This provided the nursing staff an opportunity to further discuss and support notions about the state of the patient through observations, signs and so forth. The staff described how difficult it was to maintain an objective approach working closely with the patient. They described how they at times incorrectly believed the patient to be in a better state of health than they actually were. In this sub-theme, the intellectual work on creating support for the individual conviction, providing arguments and "proves" for a certain interpretation of the patient health state, is reflected. One of the nurses putted it as follows: "...and then we together discuss and negotiate, and sometimes we even think that he/she (the patient) is better... compared to the judgement of the HCR assessment team, and they ask if we have considered this or that ... risk assessments are worth gold... he (one of the assessors) isn 't as close to the patients, and we are more blinded by familiarity...".

\subsection{Theme 2. Experiencing the RA as Being a Contra Caring Praxis}

Experiences under this theme revealed that the RA did not have an impact on daily forensic care. Rather, the RA was found to be "disturbing incidences" in the work, which was why the nursing staff did not rely on it. This was mostly because the RA did not guide or help the nursing staff in establishing interpersonal relationships with the forensic patients. In this respect, the nursing staff felt that the RA prevented them from establishing interpersonal relationships with the forensic patients, and as being in contradiction to the essence of caring. The staff preferred to spend time thinking about how to proactively create a calm and safe care environment. They described how they worked in a manner in which they tried to be observant about patients' behavior and signs of aggression, and they also intervened to prevent tension between patients. The participants emphasized the importance of communicating information about the state of the patient to other staff. One important dimension in this work was that they were given opportunities to discuss and reflect upon situations and incidences that, despite the good intensions of aggression prevention, had a negative or violent outcome. The theme was built upon two sub-themes: Having a non-instrumental patient view and Being reluctant in terms of the RA.

\subsubsection{Having a Non-Instrumental Patient View}

Despite the court requiring a structured RA as to be able to make a determination on future care, the staff were dedicated to ensuring that the instrumental approach should intertwine with a holistic patient view. This sub-theme included ideas along this line. The nursing staff made it clear that they did not bother with the RA scores; instead, they focused on how the patients felt and behaved. The nursing staff tried to work with the patient using a "here-and-now approach". They noticed the patient's tiny, tiny steps of positive change. The staff pointed out that daily clinical assessments of the patients, based on their appearance and any meetings with them, provided a basis for future care. One interviewee stated the following: “... the specific question about HCR 20... well, I don't think that I give it much thought when I'm working with them (the patients)... It is more a case of... my feeling is that it is more for others who haven't met the person in question. Yes, they want everything in black and white... they want to see that stuff is happening... for example, administrative law.

In some cases, the nursing staff carried out a less formal clinical assessment than that of the HCR 20 team. The HCR 20 team had considered one specific patient to be a high-risk patient; nonetheless, the nursing staff decided to take the aggressive patient outside for a walk. The decision to take this risk was made by the care team, whose gut feeling told them they were indeed taking a risk. On hindsight, their assessment proved itself to be accurate, and the action taken was felt to be one that supported relational build with the patient: "....we dared to do what we did, and took the patient out for a walk...//...we got some fresh air and discussed the problem. The patient got rid of some of his negative energy and the incident ended positively..."

\subsubsection{Being Reluctant in Terms of RA}

Some participants disliked the procedures that related to how the RA became "public knowledge" for other staff. Their dislike was, on the one hand, based on a concern with jeopardizing patient integrity and a wish to protect the patient's confidentiality in terms of the crime that resulted in forensic custody. On the other hand, the sense of reluctance to use the RA was based on the combined role of being both a care provider as well as an assessor of risk, where the staff's written and documented notes were accessible to the patient. Another aspect of this sub-theme was that the assessments were generally not felt to be reliable. This was due to circumstances, one being that it was not necessarily the same RA team that had conducted the first and the second RA. Further, some of the participants felt there to be inconsistencies between the RA results and the decisions. This is perhaps exemplified by the statement of one interviewee: "Even if the patient is considered to be a high-risk patient, he/she still can get permission to leave (the high-security forensic unit) ... you don't use the assessments; they just put them in the 
bottom drawer..."

\section{Discussion}

The aim of this study was to describe the experiences of forensic nurses with in-patient RA processes, and their implications for daily clinical forensic praxis. Based on the forensic nursing staff's experiences with daily clinical work with violence RA, it became clear that the staff has to deal with many contradictory realities. The description was about being able to balance between supporting their work with an EBP approach of RA while trying both to establish interpersonal relationships, and to allow for positive meetings with the patient.

Initially, we must keep in mind that in Sweden and in many Western countries, the use of an RA instrument is a product that has resulted from the work to protect the legal rights of those people who have been taken into custody. From this study, it is clear that the nursing staff indeed feel that their efforts to assess the risk of violence have become more structured and professionalized. Being able to use a scientifically proven approach in terms of RA instruments in complex decision-making situations contributes to a sense that quality of care can be more easily assured. Further, that in-forensic patient RA decisions can be based on more objective and reliable facts.

The work with RA was associated with continuity, and staff expressed their acceptance of this and how they felt it to be legitimate. Although the staff described how the work with an RA could be challenging, it was nevertheless apparent that they felt that a caring philosophy and an RA could coexist and did not need to be considered as counteractive in any way. Difficulties working with an RA occurred instead when staff felt that they lost their objectivity in terms of the patient or when staff perceptions of the patient did not match the RA team. The way in which professionals justify their opinions to others and the way in which they communicate their conclusions on the RA are of great importance (Storey et al., 2015). One of the most important reasons is that the information collected from RAs must be transferred into functioning risk-management plans for the patients (Voijt et al., 2011).

A number of staff also stated that an RA did not provide any help in the daily work with the patient. A factor that probably contributed to reduced acceptance of an RA was that an RA was not followed - for example, when a high risk patient was granted permission. In these cases, the RA may not have been sufficiently communicated between the staff and the RA team.

Many factors affect how a work duty can become permanent and routine within an organization. It is known that factors that influence the positive implementation of outcomes include having access to a supportive and effective management team that promotes and encourages staff to engage in teamwork in democratic decision-making processes (McCormack et al., 2002; Kitson et al., 1998). Webster and Hucker (2007), who for decades have provided valuable risk-assessment research, claim that group dynamics are important in the establishment of a good climate of cooperation within a team. They state that it is challenging to work with risk management because of tough decisions and because there is often disagreement between staff members. Therefore, good leadership and management are of great importance to the prevention of any 'splitting' within the team (Webster \& Hucker, 2007, p. 147).

It should be of greatest importance is that new employees receive training in RA, because otherwise the work duty can be seen as unnecessary or illegitimate. Illegitimate work duties are a source of work stress, and management should convey the fact that they are willing to assist and be involved when there is unwillingness within the working team (Semmer et al., 2015). Contradictory expectations cause role conflicts (Semmer, Driscoll, \& Bazaley, 2005) as well as an unwillingness to complete a work duty when the case is that staff lack a clear policy (Vojt el al., 2011).

McCormack et al., (2002) argue that a positive and value-oriented context contributes to a culture of learning. A quality assurance aspect in this study is that assessments were conducted by a team, which included staff who know the individual patient well, as well as risk assessors who had only met the patient sporadically. The assessors' role was to coordinate and lead the RA process and to provide expert knowledge in terms of risk factors to the team. The discussions by the RA team led to the assessment being both transparent and comprehensible for both staff and patients. Discussions, along with the opportunity to exchange experiences, in terms of an assessed risk could also be seen as being a continuous process of learning.

Many factors influence a patient's risk of violence and his/her mental health condition, which is why effective risk communication between professionals is one important factor in the clinical work with violence. Compassionate communication is one of the cornerstones of Peplau's psychodynamic nursing theory (Peplau, 1952/1994). Peplau argues that the nurse as well as the patient benefits when a trusting relationship develops and they learn and develop skills from each other. This learning process is probably something that staff use intuitively to assess the risk of a patient committing violence in the future. It can be assumed that staff find it challenging to translate this 
tacit knowledge and let it complement the structured RAs.

This study shows that staff do not rigidly follow the results of an RA. Through, the support of a trusting care team, nursing staff are able to dare make decisions that may seem controversial. This indicates that staff have a pragmatic approach when it comes to the work with an RA. They know that they need to use multiple sources of knowledge in order to make credible and accurate risk assessments. In this case, it was possible to base the decisions on dialogue, argument and creative thinking.

\section{Limitations of the Study}

For qualitative pieces of work, trustworthiness should be demonstrated in different aspects. One is credibility, which has established as a variation of experiences (Lundman \& Graneheim, 2004) in how nurses view RA and its impact on inpatient care in the forensic clinical practice is found. First, as a result of their long experience of working with RAs, we argue that the sample section of informants is appropriate because it suits the study purpose nicely (Guba, 1981); we further argue that we chose relevant analyses units. Secondly, through the use of citations, we are able to hear the voices of the informants and further, our presentation of the step-wise analysis makes it easy to follow. The authors also elaborated on all parts of the analysis jointly and discussed these until consensus was reached - an indication, then, of good dependability. Some limitation can be identified in the present study. The sample was derived from only one forensic clinic, which could limit the ability to generalize. Likewise, the study contains a small sample size, which makes a generalization of the results doubtful. However, transferability relates to whether or not the findings are translatable and own justice in other contexts. We believe that the reader is provided enough insight from the detailed description so as to be able to draw his or her own conclusions on the relevance of similar contexts.

\section{Conclusions}

To our knowledge, this is the first study of its kind that is about the clinical forensic context, and due to the ambiguity of the findings, with both pros and cons of using a systematic RA, it is hard to advice on its clinical implications. Nonetheless, it is important to point out the necessity of having an ongoing discussion related to forensic quality of care among all groups including the nursing staff. Besides, if the RAs are to be permanent and sustainable and if the instrument are to be used in a legally secure manner, they must receive regular support from team leadership that can provide both guidance and training to staff. This is especially important with new employees.

\section{Acknowledgments}

We acknowledge the staff at the Research and Development Department at the Sundsvall Forensic Psychiatric Hospital for all their help and cooperation with this study.

\section{Competing Interests Statement}

No conflict of interest was reported. The authors alone are responsible for the content and writing of the paper.

\section{References}

Belfrage, H. (1998). Implementing the HCR-20 scheme for risk assessment in a forensic psychiatric hospital: integrating research and clinical practice. The Journal of Forensic Psychiatry, 2, 328-338. http://dx.doi.org/10.1080/09585189808402200

Buchanan, A. (2013). Violence Risk Assessment in Clinical Settings: Being Sure about Being Sure. Behavioral Sciences and the Law, 31, 74-80. https://doi.org/10.1002/bsl.2045.

Hart, S. D., Webster, C. D., Douglas, K., \& Belfrage, H. (2013). HCR-20 V3: Assessing risk of violence. User guide. Burnaby, Canada: Mental Health, Law, and Policy Institute, Simon Frazer University.

Graneheim, U. H., \& Lundman, B. (2004). Qualitative content analysis in nursing research: concepts, procedures and measures to achieve trustworthiness. Nurse Education Today, 24, 105-112. http://dx.doi.org/10.1016/j.nedt.2003.10.001

Grol, R., \& Wensing, M. (2004). What drives change? Barriers to and incentives for achieving evidence-based practice. The Medical Journal of Australia, 180(6 Suppl.), s. 57.

Guba, E. (1981) Criteria for assessing the trustworthiness of naturalistic inquiries. Educational Technology Research \& Development, 29, 75-91. http://dx.doi.org/10.1007/BF02766777

Harvey, G., \& Kitson, A. (2016). PARIHS revisited: from heuristic to integrated framework for the successful implementation of knowledge into practice. Implementation Science 2016, 11, 33. 
https://doi.org/10.1186/s13012-016-0398-2

Kitson, A., Harvey, G., \& McCormack, B. (1998). Enabling the implementation of evidence based practice: A conceptual framework. Quality of Health Care, 7, 149-158.

McCormack, B., Harvey, G., Rycroft-Malone, J., Titchen, A., \& Seers K. (2002). Getting evidence inti practice: the meaning of 'context'. Journal of Advanced Nursing, 38, 94-104. http://dx.doi.org/10.1046/j.1365-2648.2002.02150.x.

Nilsson, T., Munthe, C., Gustavson, C., Forsman, A., \& Anckarsäter, H. (2009). The precarious practice of forensic psychiatric risk assessments. International Journal of Law and Psychiatry, 32, 400-407. https://doi.org/10.1016/j.ijlp.2009.09.010.

Olsson, H., Strand, S., Sjöling, M., \& Asplund, K. (2013). Decreased risk for violence in patients admitted to forensic care, measured with the HCR-20. Archives of Psychiatric Nursing, 4, 191-197. https://doi.org/10.1016/j.apnu.2013.03.004.

Olsson, H., Strand, S., \& Kristiansen, L. (2014). Turning towards recovery in forensic psychiatric inpatients - a study based on staff experience. Nordisk Sygeplejeforskning, 3, 175-188.

Olsson, H., Adulv, Å., Strand, S., \& Kristiansen, L. (2015). Reducing or Increasing Violence in Forensic Care: A Qualitative Study of Inpatients Experience. Achieves of Psychiatric Nursing, 29, 393-400. http://dx.doi.org/10.1016/j.apnu.2015.06.009.

Otto, R. K., \& Douglas, K. S. (2010). Handbook of violence risk assessment. New York, NY: Routledge/Taylor \& Francis Group.

Patton, M. Q. (2015). Qualitative Research \& Evaluation Methods (4th ed.). Newbury Park: SAGE Publication. London.

Peplau, H. E. (1952/1994). Interpersonal relationship in nursing: A conceptual frame of reference for psychodynamic nursing. New York: Springer.

Sackett, D. L., Richardson, W. S., Rosenberg, W., \& Haynes, R. B. (1997). Evidence Base Medicine. How to Practice and Teach? EBM. Churchill Livingstone, Edinburgh.

Salzmann-Erikson, M., Rydlo, C., \& Wiklund Gustin, L. (2016). Getting to know the person behind the illness the significance of interacting with patients hospitalised in forensic psychiatric settings. Journal of Clinical Nursing, 25, 1426-1434. https://doi.org/10.1111/jocn.13252.

Samuel, A., O'Driscoll., \& Bazaley, M. (2005). Combining Clinical and Actuarial Methods to Assess and manage Risk in a New South Wales Forensic Psychiatric Setting. Australasian Psychiatry, 13, 285-290. doi:10.1111/j.1440-1665.2005.02203.x

Semmer, N. K., McGrath, J. E., \& Beehr, T. A. (2005). Conceptual issues in research on stress and health. In C. L. Cooper, (Ed.), Handbook of stress medicine and health (2nd ed.). New York, NY: CRC Press; 2005.

Semmer, N. K., Jacobshagen, N., Meier, L. L., Elfering, A., Beehr, T. A., Kälin, W., \& Tschan, F. (2015). Illegitimate tasks as a source of work stress. Work \& Stress, 29, 32-56. https://dx.doi.org/10.1080\%2F02678373.2014.1003996.

SFS 2017:30 Svensk Författningssamling. (Swedish Code of Statutes) (2017). Law on Health Care Act. Department of Justice. https://www.riksdagen.se/sv/dokument-lagar/dokument/svensk-forfattningssamling/ halso--och-sjukvardslag_sfs-2017-30

SFS 2017:38 Svensk Författningssamling. (Swedish Code of Statutes) (2017). Law on Forensic psychiatric care. Department of Justice. http://rkrattsdb.gov.se/SFSdoc/17/170038.PDF.

Singh, J. P., Grann, M., \& Fazel, S. (2011). A comparative study of risk assessment tools: A systematic review and metaregression analysis of 68 studies involving 25,980 participants. Clinical Psychology Review, 31, 499-513. https://doi.org/10.1016/j.cpr.2010.11.009.

Singh, J. P., Fazel, S., Gueorguieva, R., \& Buchanan, A. (2014). Rates of violence in patients classified as high risk by structured risk assessment instrument. The British Journal of Psychiatry, 204, 180-7. https://doi.org/10.1192/bjp.bp.113.131938.

Storey, J. E., Watt, K. A., \& Hart, S. D. (2015). An Examination of Violence Risk Communication in Practice Using a Structured Professional Judgment Framework. Behavioral Sciences and the Law, 33, 39-55. https://doi.org/10.1002/bsl.2156. 
Vojt, G., Slesser, M., Marchall, L., \& Thomson, L. (2011). The clinical reality of implementing formal risk assessment and management measures within high secure forensic care. Medicine, Sciences and Law, 51, 220-227.

Webster, C. D., Douglas, K. S., Eaves, S. D., \& Hart, S. D. (1997). HCR-20: Assessing the risk for violence (version 2). Vancouver, Canada: Simon Fraser University, Mental Health, Law, and Policy Institute.

Webster, C. D., \& Hucker, S. J. (2007). Violence Risk. Assessment and Management. John Wiley \& Sons, Ltd. The Atrium, Southern Gate, Chichester, West Sussex, England.

\section{Copyrights}

Copyright for this article is retained by the author(s), with first publication rights granted to the journal.

This is an open-access article distributed under the terms and conditions of the Creative Commons Attribution license (http://creativecommons.org/licenses/by/4.0/). 